\title{
Verification and validation of a CFD model of a fixed regenerator for heat recovery from air
}

\author{
Angel Penev ${ }^{1, *}$, Lyubomir Tsokov ${ }^{1}$, and Momchil Vassilev ${ }^{1}$ \\ ${ }^{1}$ Technical University of Sofia, Thermal and Refrigeration Engineering Department, Sofia, Bulgaria
}

\begin{abstract}
The article presents verification and validation of a numerical model of conjugated heat and mass transfer processes and aerodynamics in a fixed "honeycomb" type regenerator with square channels for heat recovery from the exhaust air of a local ventilation system. The processes in the regenerator are simulated by the CFD method. The influence of the processes of condensation and evaporation of moisture in the humid air on the efficiency of the regenerator has been investigated through these simulations and is shown in the article. The calculations of the fixed regenerator's thermal efficiency and pressure losses are made by known analytical models and the results are compared with those of the numerical model. The article compares the model simulation results with experimental data and data from reference sources.
\end{abstract}

\section{Introduction}

Regenerative heat exchangers are often used to recover heat from the exhaust air to the supply air in ventilation and air conditioning systems. A wide range of regenerators is available on the market in terms of operating mode, geometry, and heat storage material. Standardized tests are used to determine the parameters of the air flows and the thermal efficiency of the regenerators. These tests use stationary conditions - constant temperatures, humidity, and flows. Usually, the duration of the regeneration cycle is chosen by the manufacturers. The regenerative heat exchangers, built into the air conditioning units, operate under not constant conditions. In such devices, the parameters of hot and cold airflow vary depending on the climate and conditions in the room. This unbalances the operation of the heat exchanger and affects its efficiency, which is evidenced by measurements performed on-site and published in various articles, [1-3]. Mathematical modeling and numerical simulation under different conditions and durations of the regenerator cycle can be used to study and analyze the operation of such regenerators. The tasks that can be solved by using sufficiently accurate and flexible models of such heat exchangers are important for the optimization of the devices in which these regenerators are mounted.

The article presents the verification and validation of a new CFD model of a fixed bed regenerator, [4]. The accuracy of the model is shown and a comparison is made with the results of well-known methods for calculating such regenerative heat exchangers. The

\footnotetext{
*Angel Penev: gartz@tu-sofia.bg
} 
comparison allows evaluating the possibilities of these methods to be used in the design of regenerators operating in similar conditions.

\section{Methods statement}

\subsection{Analytical method}

The paper uses the well-known analytical method to determine the efficiency of the regenerator - the " $\Lambda$ - $\Pi$ " method developed by Hausen, $[5,6]$. The " $\Lambda-\Pi$ " method is specifically aimed at fixed regenerators with periodic mode, which correspond to the dimensionless variables " $\Lambda$ " for reduced length and " $\Pi$ " for the reduced period. This method allows the evaluation of the efficiency of the regenerator with engineering accuracy in the operation of the regenerator with dry air. It is obtained on the basis of solutions of simplified one-dimensional differential models of the processes, with constant average thermophysical properties of the air and the matrix. The average values of the heat transfer coefficient between the matrix and the hot and cold air flows participate as parameters in the equations of the analytical model. They are calculated by appropriate criterion equations for the Nusselt number, [7-9].

\subsection{Numerical method}

For the computer simulations, a physical-mathematical model of a fixed regenerator with a counterflow arrangement was used. The model describes a complex transient conjugate process of heat and mass transfer. It can be used for moist air with and without processes of condensation and evaporation on the surface of the wall of the matrix channel, but without fog formation in the flow, $[10,11]$. To solve the system of differential equations, the CFD method was used, namely the Finite Volume Method, [12]. The numerical procedure was implemented through the ANSYS - Fluent software, [13].

\subsubsection{Geometry and mesh}

The adiabatic symmetry of the matrix allows being reduced to a single channel with the halfthickness of its walls, Fig.1. The front surfaces of the solid walls are also assumed to be adiabatic. The fine mesh contains 1880855 nodes and 439560 elements, recommended for the correct Courant number. The setup for meshing is "inflation" with connections between solid domain and fluid domain. This mesh is recommended for Eulerian wall film model. The number of time steps is 0.01 .
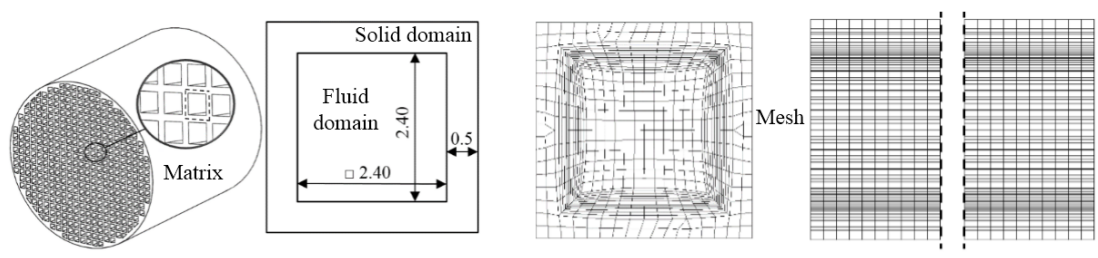

Fig. 1. The matrix, computational domains and mesh.

\subsubsection{Algorithm of the model}


The algorithm of the computerized model provides automatic switching of the heating and cooling periods to reach a quasi-steady-state solution, Fig.2. The flow is laminar.

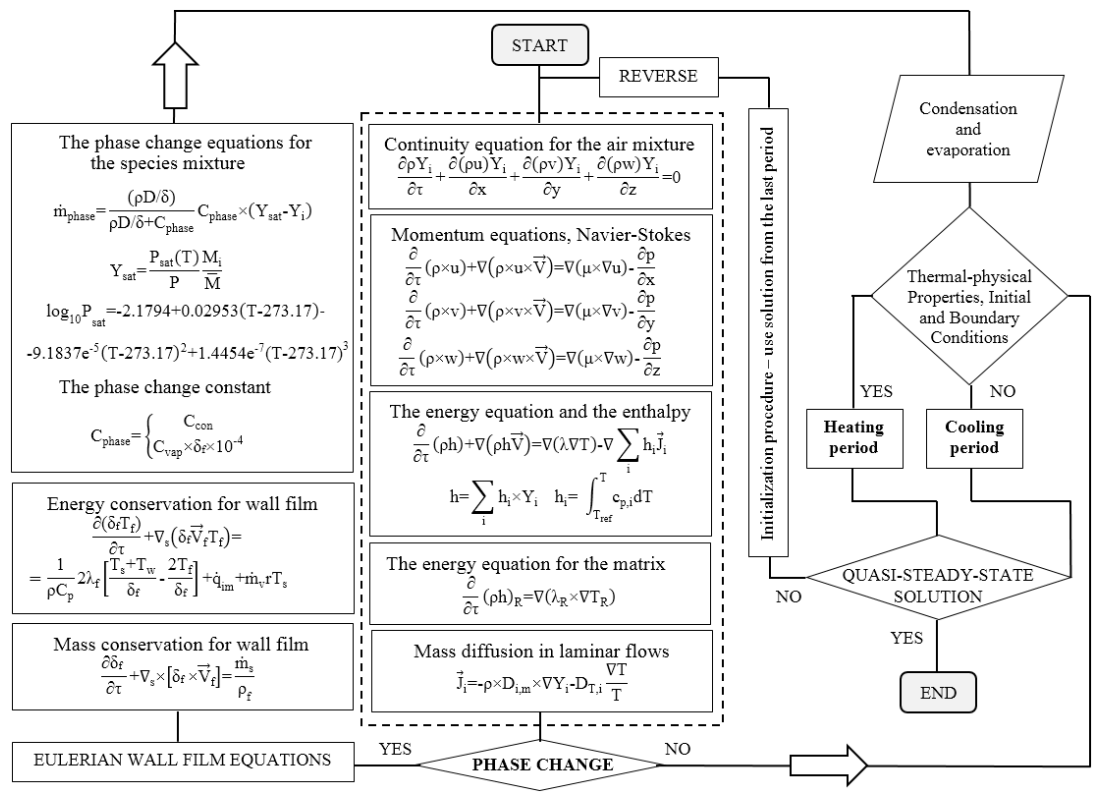

Fig. 2. Algorithm of the new CFD model.

The descriptions of the variables from the system equations are given in Table 1.

Table 1.Nomenclature of the numerical model.

\begin{tabular}{|c|c|}
\hline Variable & Descriptions and dimensions, [unit] \\
\hline $\mathrm{V}, \mathrm{u}, \mathrm{v}, \mathrm{w}$ & vector of the velocity of the airflow and its orthogonal projections, $[\mathrm{m} / \mathrm{s}]$ \\
\hline$\rho, \lambda, \mathrm{c}_{\mathrm{p}}, \mu, \mathrm{d}$ & $\begin{array}{l}\text { density, }\left[\mathrm{kg} / \mathrm{m}^{3}\right] \text {, thermal conductivity, }[\mathrm{W} / \mathrm{m} . \mathrm{K}] \text {, heat capacity at } \mathrm{p}=\text { const, } \\
{[\mathrm{J} / \mathrm{kgK}], \text { and dynamic viscosity, }\left[\mathrm{N} . \mathrm{s} / \mathrm{m}^{2}\right] \text {, specific humidity, }[\mathrm{g} / \mathrm{kg}]}\end{array}$ \\
\hline$\rho_{\mathrm{r}}, \lambda_{\mathrm{r}}, \mathrm{c}_{\mathrm{r}}$ & $\begin{array}{l}\text { density of the regenerator matrix, }\left[\mathrm{kg} / \mathrm{m}^{3}\right] \text {, thermal conductivity of the } \\
\text { regenerator, }[\mathrm{W} / \mathrm{m} . \mathrm{K}] \text {, and heat capacity of the regenerator, }[\mathrm{J} / \mathrm{kgK}]\end{array}$ \\
\hline $\mathrm{Y}_{\mathrm{i}}$ & mass fraction for i-th species, $\left[\mathrm{kg}_{\mathrm{i}} / \mathrm{kg}_{\text {mixture }}\right]$ \\
\hline $\mathrm{J}_{\mathrm{i}}$ & mass diffusion flux for laminar flow, $\left[\mathrm{kg} / \mathrm{m}^{2} \mathrm{~s}\right]$ \\
\hline $\mathrm{D}, \mathrm{D}_{\mathrm{i}, \mathrm{m}}, \mathrm{D}_{\mathrm{T}, \mathrm{i}}$ & $\begin{array}{l}\text { mass diffusion coefficient, mass diffusion coefficient for } \mathrm{i} \text {-th species and } \\
\text { thermal mass diffusion coefficient, }\left[\mathrm{m}^{2} / \mathrm{s}\right]\end{array}$ \\
\hline $\mathrm{P}_{\text {sat }}, \mathrm{P}$ & saturation pressure and absolute pressure, $[\mathrm{Pa}]$ \\
\hline $\mathrm{T}, \mathrm{T}_{\mathrm{r}}, \mathrm{T}_{\mathrm{s}}, \mathrm{T}_{\mathrm{f}}$ & $\begin{array}{l}\text { temperature of the flow, temperature of the regenerator, temperature of the } \\
\text { film, average temperature of the film, }[\mathrm{K}] \text { or }\left[{ }^{\circ} \mathrm{C}\right]\end{array}$ \\
\hline$\delta, \delta_{\mathrm{f}}$ & distance from the grid cell center to the wall and the film height, $[\mathrm{m}]$ \\
\hline $\mathrm{M}_{\mathrm{i}}, \mathrm{M}$ & molecular weight of the vapour species and the mixture, $[\mathrm{kg} / \mathrm{kmol}]$ \\
\hline$\dot{\mathrm{m}}_{\text {phase }}, \dot{\mathrm{m}}_{\mathrm{s}}, \dot{\mathrm{m}}_{\mathrm{v}}$ & $\begin{array}{l}\text { rate of phase change, rate of mass source per unit wall area due to droplet } \\
\text { collection, mass rate of the evaporation and the condensation, }\left[\mathrm{kg} / \mathrm{m}^{2} \mathrm{~s}\right]\end{array}$ \\
\hline $\mathrm{h}, \mathrm{h}_{\mathrm{r}}$ & specific enthalpy of the species mixture and the regenerator, $[\mathrm{J} / \mathrm{kg}]$ \\
\hline $\mathrm{C}_{\text {phase }}, \mathrm{C}_{\text {con }}, \mathrm{C}_{\text {vap }}$ & phase change constant, condensation constant and evaporation constant \\
\hline$\dot{\mathrm{q}}_{\mathrm{im}}$ & source term due to liquid impingement from the bulk flow to the surface \\
\hline $\mathrm{r}, \mathrm{q}$ & latent heat associated with the phase change, $[\mathrm{J} / \mathrm{kg}]$, heat flux, $\left[\mathrm{W} / \mathrm{m}^{2}\right]$ \\
\hline
\end{tabular}




\subsubsection{Initial and boundary conditions}

The boundary conditions of the heat transfer between the airflow and the regenerator's matrix are as follow:

$$
\mathrm{T}_{\mathrm{w}}=\mathrm{T}_{\mathrm{r}, \mathrm{w}}
$$

where: $T_{w}, T_{r, w}$ are the temperatures of the air and the matrix on the surface of the channel.

The simulation starts from the state of heat-mass equilibrium:

$$
\mathrm{T}_{\mathrm{r}}(\mathrm{x}, \mathrm{y}, \mathrm{z}, 0)=\mathrm{T}(\mathrm{x}, \mathrm{y}, \mathrm{z}, 0)=\mathrm{T}_{\mathrm{o}}, \quad \mathrm{Y}_{\mathrm{wv}}(\mathrm{x}, \mathrm{y}, \mathrm{z}, 0)=\mathrm{Y}_{\mathrm{wv}, \mathrm{o}} \quad 0 \leq \mathrm{x} \leq \mathrm{L}
$$

For each flow switching, the temperature field in the regenerator and the air at the end of the heating or cooling half-cycle period are saved and set as the initial condition for the next half-period. The process of periodic heating and cooling of the matrix continues until reaching a quasi-steady-state solution. The time required to switch is negligibly small.

$$
\mathrm{T}_{\mathrm{r}, \mathrm{h}}\left(\mathrm{x}, \mathrm{y}, \mathrm{z}, \tau_{\mathrm{h}}\right)=\mathrm{T}_{\mathrm{r}, \mathrm{c}}\left(\mathrm{x}, \mathrm{y}, \mathrm{z}, \tau_{\mathrm{h}, 0}=0\right) \quad \mathrm{T}_{\mathrm{r}, \mathrm{h}}\left(\mathrm{x}, \mathrm{y}, \mathrm{z}, \tau_{\mathrm{h}, 0}=0\right)=\mathrm{T}_{\mathrm{r}, \mathrm{c}}\left(\mathrm{x}, \mathrm{y}, \mathrm{z}, \tau_{\mathrm{c}}\right)
$$

The boundary conditions have periodic-flow conditions with constant inlet parameters during the heating/cooling period.

$$
\begin{array}{llll}
\mathrm{T}_{\mathrm{h}}\left(0, \mathrm{y}, \mathrm{z}, \tau_{\mathrm{h}, \tau}\right)=\mathrm{T}_{\mathrm{h}, \mathrm{i}} & \mathrm{Y}_{\mathrm{wv}, \mathrm{h}}\left(0, \mathrm{y}, \mathrm{z}, \tau_{\mathrm{h}, \tau}\right)=\mathrm{Y}_{\mathrm{wv}, \mathrm{h}, \mathrm{i}} & \mathrm{u}_{\mathrm{i}, \mathrm{h}}\left(0, \mathrm{y}, \mathrm{z}, \tau_{\mathrm{h}, \tau}\right)=\mathrm{u}_{\mathrm{i}, \mathrm{h}} & 0 \leq \tau \leq \tau_{\mathrm{h}} \\
\mathrm{T}_{\mathrm{c}}\left(\mathrm{L}, \mathrm{y}, \mathrm{z}, \tau_{\mathrm{c}, \tau}\right)=\mathrm{T}_{\mathrm{c}, \mathrm{i}} & \mathrm{Y}_{\mathrm{wv}, \mathrm{c}}\left(\mathrm{L}, \mathrm{y}, \mathrm{z}, \tau_{\mathrm{c}, \tau}\right)=\mathrm{Y}_{\mathrm{wv}, \mathrm{c}, \mathrm{i}} & \mathrm{u}_{\mathrm{i}, \mathrm{c}}\left(\mathrm{L}, \mathrm{y}, \mathrm{z}, \tau_{\mathrm{c}, \tau}\right)=-\mathrm{u}_{, \mathrm{i}, \mathrm{c}} & 0 \leq \tau \leq \tau_{\mathrm{c}}
\end{array}
$$
where: $\mathrm{u}$ is the velocity of the flow $\mathrm{x}=0$ and $\mathrm{x}=\mathrm{L}, \mathrm{m} / \mathrm{s}$; subscripts " $\mathrm{i}$ " and " $\mathrm{o}$ "-inlet and outlet; subscript " $m$ " indicates the average value for the flow and " $\tau$ " indicates the current moment of the period; subscripts " $c$ " and " $h$ " indicate cold and hot flow and ,wv" indicates water vapour of mass fraction; "i" - sequence number of the cycle.

\subsubsection{Values of the initial and boundary conditions}

Equal initial temperatures of the regenerator and the air in the channel $\mathrm{T}_{\mathrm{o}}=\mathrm{T}_{\mathrm{r}}=\mathrm{T}=0^{\circ} \mathrm{C}$ are set zero, $\mathrm{T}_{\mathrm{O}}=\mathrm{T}_{\mathrm{R}}=\mathrm{T}=0^{\circ} \mathrm{C}$. The outlet gauge pressure during the heating and cooling period is zero, $\mathrm{p}=0 \mathrm{~Pa}$. Constant inlet temperatures during the heating and cooling period are $\mathrm{T}_{\mathrm{h}, \mathrm{i}}=20^{\circ} \mathrm{C}$ and $\mathrm{T}_{\mathrm{c}, \mathrm{i}}=0^{\circ} \mathrm{C}$. Constant inlet mass fractions of water vapour during the heating and cooling period are $\mathrm{Y}_{\mathrm{h}, \mathrm{i}}=0.00321$ and $\mathrm{Y}_{\mathrm{c}, \mathrm{i}}=0.00213$, which simulate dry conditions with approximately indoor relative humidity $25 \%$ and outdoor relative humidity $53 \%$. The equal durations of the two half-periods are $\tau_{\mathrm{h}}=\tau_{\mathrm{c}}=90 \mathrm{~s}$.

\subsubsection{Physical properties of air and honeycomb matrix}

The average physical properties of the humid air at absolute pressure $p=94659 \mathrm{~Pa}$ for the temperature range of $0.0 \leq \mathrm{T}{ }^{\circ} \mathrm{C} \leq 20.0$ and the inlet humidity range of $2.14 \leq \mathrm{d} \mathrm{g} / \mathrm{kg} \leq 11,7$ and the thermal properties of ceramic materials are shown below in Table 2.

Table 2.Thermal properties of the air and matrix materials.

\begin{tabular}{|c|c|c|c|c|}
\hline Name / Unit & $\rho, \mathrm{kg} / \mathrm{m}^{3}$ & $\mathrm{c}_{\mathrm{p}}, \mathrm{J} / \mathrm{kgK}$ & $\lambda, \mathrm{W} / \mathrm{mK}$ & $\mu$, Pa.s \\
\hline Humid Air & $\rho=\mathrm{p} / \mathrm{RT}$ & $\mathrm{c}_{\mathrm{p}}=1010$ & $\lambda=0.02517$ & $\mu=1.676 \mathrm{e}-5$ \\
\hline Water Vapour & $\rho=\mathrm{p} / \mathrm{RT}$ & $\mathrm{c}_{\mathrm{p}}=1896$ & $\lambda=0.01721$ & $\mu=9.461 \mathrm{e}-6$ \\
\hline Water Liquid & $\rho=999$ & $\mathrm{c}_{\mathrm{p}}=4196$ & $\lambda=0.5803$ & $\mu=1.306 \mathrm{e}-3$ \\
\hline Dense Cordierite & $\rho_{\mathrm{r}}=2100$ & $\mathrm{c}_{\mathrm{r}}=900$ & $\lambda_{\mathrm{r}}=1.5$ & - \\
\hline Ceramic - NiCrBSi & $\rho_{\mathrm{r}}=2107$ & $\mathrm{c}_{\mathrm{r}}=495$ & $\lambda_{\mathrm{r}}=5.7$ & - \\
\hline
\end{tabular}

\subsection{Experimental equipment}

\subsubsection{Aerodynamic characteristics test bench}


A test bench complying with the requirements of the AMCA 210 standard (ISO 5801) is used to measure the aerodynamic characteristics of the regenerator - flow rate and pressure drop, [14]. A drawing of the test bench is presented in Fig.3.

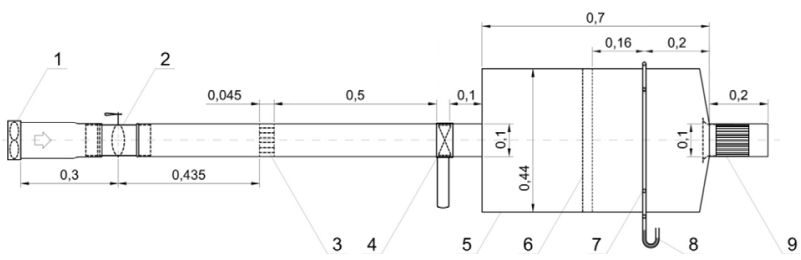

Fig. 3. The test bench for regenerator pressure drop measurement.

The airflow through the channel of the test bench is induced by fan 1 . The value of the airflow can be set by the control valve 2 and after passing the airflow rectifier 3 is measured with an anemometer 4 , with an accuracy of $\pm 3 \%$. The pressure drop through the regenerator 9 is measured at position 8 with a differential pressure gauge to within $\pm 1 \%$.

\subsubsection{Thermal efficiency test equipment}

The air handling unit for heat recovery from the exhaust air is shown in Fig.4. The ventilation device consists of two fans, position 3 for the exhaust fan and position 7 for the supply fan, and the ceramic matrix of the regenerator, position 5 . The dimensions of the matrix are diameter $\varnothing 93 \mathrm{~mm}$, length $99 \mathrm{~mm}$, and square channels $2.4 \mathrm{~mm} \times 2.4 \mathrm{~mm}$ with wall thickness around $1 \mathrm{~mm}$.

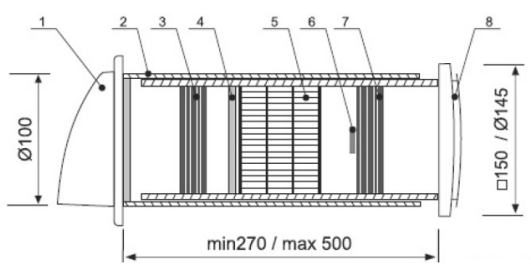

Fig. 4. The regenerative device for heat recovery from air: 1 - outdoor grid, 2 - thermally insulated air duct, 3 - exhaust fan, 4 - filters, 5 - matrix, 6 - ionizer, 7 -supply fan, 8 - indoor grid.

In order to experimentally determine the thermal efficiency of the regenerator, the device was mounted in a wall separating two spaces with different air temperatures, [15]. The air temperature in the low-temperature volume is not kept constant. For this reason, in the process of the experiment, the inlet temperature of the cold flow increases very smoothly due to the exchange of air between the two spaces. Temperatures are measured with low inertia temperature sensors. The time step in the temperature measurement is $0.5 \mathrm{~s}$.

\section{Results}

\subsection{Assessment of the aerodynamic}

This section compares the aerodynamic characteristics of the regenerator, obtained in three different ways - known analytical equations [16, 17], numerical results from computer simulations, and experimental measurements described above. The results for the pressure drop in the regenerator depending on the airflow rate, obtained in the three ways, are presented in the graph in Fig.5. 


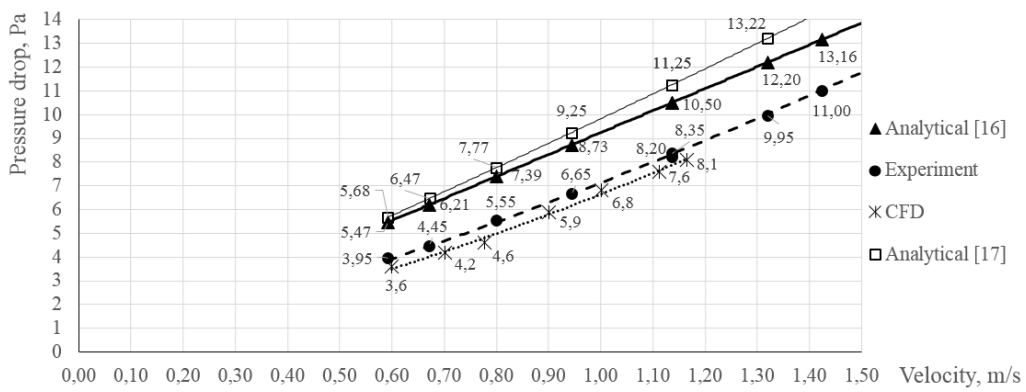

Fig. 5. Correlations of the pressure drop vs the flow rate of the regenerator

The error of the analytical correlations with respect to the result of the experiment reaches $50 \%$ for the low flow rates. The difference between the results of the CFD calculations and the experimental data at the same flow rate is minus $9 \%$, but the CFD solution does not include local pressure losses at the inlet and outlet of the matrix. The analytical solutions include all pressure losses in the channel.

\subsection{Assessment of the thermal efficiency}

In this section, a comparison is made of the values of thermal efficiency of the regenerator, obtained by three different methods - analytical, numerical, and experimental. The evaluation of the thermal efficiency by all three methods refers to the operation of the regenerator with humid air, but without the occurrence of phase transition processes in the channels of the matrix.

The physical properties of the regenerative matrix were selected from reference data by the measured value of the dense cordierite density (Table 2).

Experimental thermal efficiency data were obtained for an unbalanced regenerator. The velocities of unbalanced airflows in the matrix during the half-periods are:

$$
\begin{array}{cc}
\mathrm{u}_{\mathrm{i}, \mathrm{h}}\left(0, \mathrm{y}, \mathrm{z}, \tau_{\mathrm{h}, \tau}\right)=\mathrm{u}_{\mathrm{i}, \mathrm{h}}=0.6 & 0 \leq \tau \leq 90 \\
\mathrm{u}_{\mathrm{i}, \mathrm{c}}\left(\mathrm{L}, \mathrm{y}, \mathrm{z}, \tau_{\mathrm{c}, \tau}\right)=-\mathrm{u}_{\mathrm{i}, \mathrm{c}}=-0.5 & 0 \leq \tau \leq 90
\end{array}
$$

The inlet and outlet temperatures on both sides of the regenerator, obtained as a result of the numerical simulations and the experiment, are compared in Figure 6.

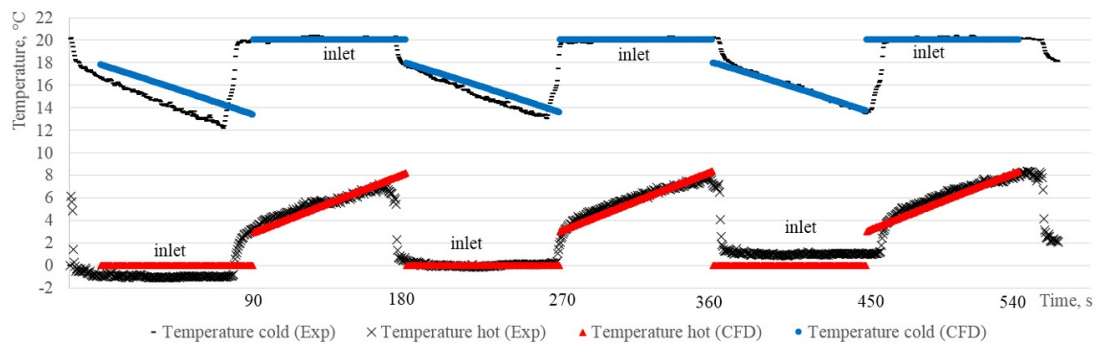

Fig. 6. Flow temperature curves on both sides of the regenerator

The visual comparison of the temperature curves shows a very good match. It can be seen that the difference between the amplitudes of the temperature curves is due to the slow increase in the inlet temperature of the cold flow, as noted in section 2.3.2. The discrepancy of the curves over time is due to the fact that the switching of the flows in the experiment is not instantaneous. 
The calculated values of thermal efficiency by the three methods (analytical, numerical, and experimental) are shown on the bar chart in Fig.7.

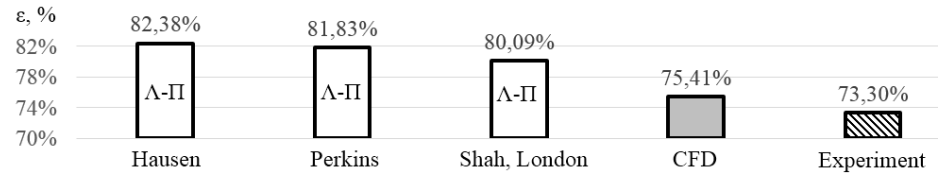

Fig. 7. Bar diagram of thermal efficiency

The bar chart shows three different values of thermal efficiency, calculated by " $\Lambda$ - $"$ method for three different values of the Nusselt number, obtained from three equations for laminar flow in a channel, of Hausen $(\mathrm{Nu}=3.76)$, Perkins $(\mathrm{Nu}=3.61)$, Shah and London $(\mathrm{Nu}=3.19)$, where the values of $\mathrm{Nu}$ are averaged over the two heating and cooling halfperiods.

\subsection{Influence of phase change on the thermal efficiency}

The influence of the phase transition processes in the matrix channels on the regenerator efficiency was evaluated approximately by upgrading the validated model and under the same boundary conditions as in section 2.2.3 with several differences. The differences are in the thermal properties of ceramic NiCrBSi (Table 2), the inlet velocities $\left(\mathrm{u}_{\mathrm{i}, \mathrm{h}}=\mathrm{u}_{\mathrm{i}, \mathrm{c}}=0,7\right)$, and the mass fraction of the water vapor of the exhaust air, which corresponds to a relative humidity of the air in the room $73 \%$.

$$
\begin{array}{cc}
\mathrm{Y}_{\mathrm{wv}, \mathrm{h}}\left(0, \mathrm{y}, \mathrm{z}, \tau_{\mathrm{h}, \tau}\right)=\mathrm{Y}_{\mathrm{wv}, \mathrm{h}, \mathrm{i}}=0.0116 & 0 \leq \tau \leq 90 \\
\mathrm{Y}_{\mathrm{wv}, \mathrm{c}}\left(\mathrm{L}, \mathrm{y}, \mathrm{z}, \tau_{\mathrm{c}, \tau}\right)=\mathrm{Y}_{\mathrm{wv}, \mathrm{c}, \mathrm{i}}=0.00213 & 0 \leq \tau \leq 90
\end{array}
$$

Under these conditions, there is no water accumulation in the periods and the condensate was completely evaporated during the cooling period.

The inlet and outlet temperatures on both sides of the regenerator, obtained as a result of the numerical simulations with and without phase change of the moisture in the matrix channel, are compared in Figure 8.

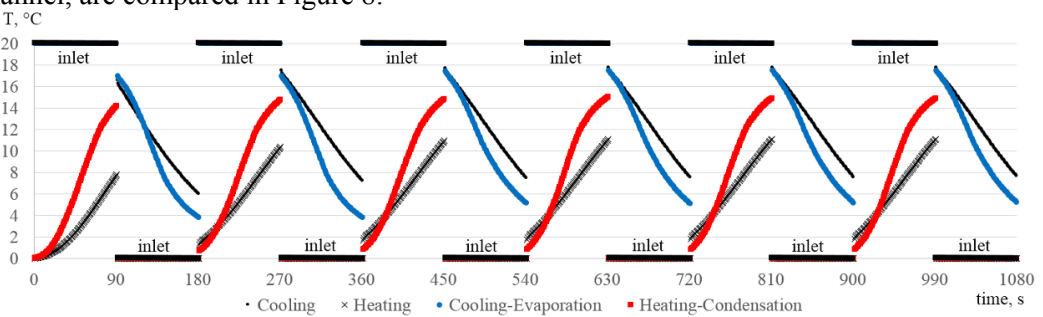

Fig. 8. Flow temperature curves on both sides of the matrix for air with and without phase change.

Condensation and evaporation processes under these conditions reduce the thermal efficiency of the regenerator from $67.8 \%$ to $58.2 \%$. This decrease is due to the complex heat and mass transfer in the matrix channels and the different heat transfer coefficients, which the existing analytical methods cannot take into account. It should be noted that the validation of the simulation results with the presence of a phase transition has not been performed. The differential mathematical model used does not include the formation of fog in the airflow, but allows an increase in relative humidity above $100 \%$, simulating supersaturated vapour. The used computational model was verified by comparing the results of simulations with similar ones from the article, [18]. 


\section{Conclusion}

A CFD model of fixed matrix regenerative heat exchanger for decentralized ventilation for humid air with and without water vapour condensation on the wall of the channels is presented. The article shows that the CFD model of the processes in the regenerator significantly surpasses the analytical models not only in terms of the range of boundary conditions, but also in terms of accuracy. The computational model was tested by analytical solutions and validated by experimental data and it was found that the results of the simulation for humid air without condensation and evaporation are quite accurate and reliable. The results of simulations with the phase change in the channels are not validated but the model is verified with similar solutions. They are indicative and show that the reduction in thermal efficiency under the boundary conditions used is about $10 \%$ and depends on the thermal properties of the regenerator's material, [19].

This article is subject of the study of the author's $\mathrm{PhD}$ dissertation.

\section{References}

1. A. Mikola, R. Simson, J. Kurnitski, Energies, 12(13), 2633, (2019).

2. A. Merzkirch, S. Maas, F. Scholzen, D. Waldmann, The 45. International HVAC\&R Congress, Zbornik Međunarodnog kongresa o KGH, 45(1), (2017).

3. A. Penev, L. Tsokov, 6th International Symposium on Environment-Friendly Energies and Applications, IEEE, 116(6), pp. 154-159, (2021).

4. W. L. Oberkampf, T. G. Trucano, Prog. Aerosp. Sci., 38(3), pp. 209-272, (2002).

5. H. Hausen, Heat Transfer in Counterflow, Parallel Flow and Cross Flow, McGraw-Hill Book Company, (1983).

6. K. Thulukkanam, Heat exchanger design handbook, CRC press, (2013).

7. R. K. Shah, A. L. London, Laminar flow forced convection in ducts: a source book for compact heat exchanger analytical data, Academic press, (2014).

8. W. H. Mcadams, Heat Transmission: $3 d$ Ed., McGraw-Hill, (1954).

9. A. Penev, L. Tsokov, The Scientific Journal of BulCToMM, Varna, 124, (2020).

10. A. Penev, L. Tsokov, N. Penkova, J. Chem. Technol. Metall., 55(5), (2020).

11. A. Penev, L. Tsokov, 6th International Symposium on Environment-Friendly Energies and Applications, IEEE, 116(6), pp. 164-170, (2021).

12. J. D. Anderson, Computational fluid dynamics. The basic with application. New York, McGraw-Hill, Inc., (1995).

13. Fluent, ANSYS Fluent user's guide, Ansys Inc, (2009).

14. M. Vassilev, L. Tsokov, XXI Scientific Conference with International Participation FPEPM, Sozopol, pp. 169-174, (2016).

15. L. Tsokov, N. Kaloyanov, XX National Scientific Conference with International Participation FPEPM, Sozopol, pp. 333-337, (2015).

16. R. K. Shah, D. P. Sekulic, Fundamentals of heat exchanger design. John Wiley \& Sons, (2003).

17. N. Monarkin, S. Lukin, Y. M. Anurov, B. A. Tihomirov, G. A. Agasiants, S. M. Galileev, and T. R. Akhmetov, IOP Conf. Ser.: Earth Environ. Sci., 337, (2019).

18. M. Nizovtsev, V. Borodulin, V. Letushko, Appl. Therm. Eng., 111, (2017).

19. A. Penev, L. Tsokov, E3S Web Conf., 207, 01001, (2020). 